\title{
ERRATUM
}

Valentina Bassareo $\cdot$ Gianluigi Tanda

Paola Petromilli · Corrado Giua - Gaetano Di Chiara

\section{Non-psychostimulant drugs of abuse and anxiogenic drugs activate with differential selectivity dopamine transmission in the nucleus accumbens and in the medial prefrontal cortex of the rat}

Psychopharmacology (1996) 124:293-299

After publication of the above article, the authors supplied corrected versions of Figs. 5, 6 and 8, which are now published below.

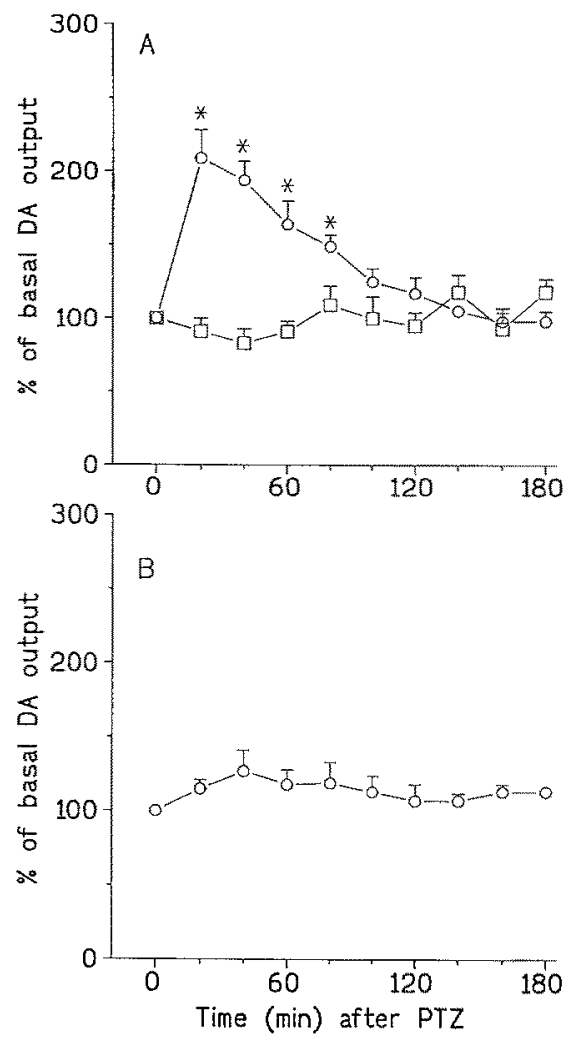

Fig. 5 A, B Effect of pentylentetrazole (PTZ) $(O 20 \mathrm{mg} / \mathrm{kg} \mathrm{IP;} \square$ $10 \mathrm{mg} / \mathrm{kg}$ IP) on DA output in dialysates from the prefrontal cortex $(\mathbf{A})$ and from the nucleus accumbens $(\mathbf{B})$. Results are meanstSEM of the results obtained in at least four rats. $* P<0.05$ com pared with basal values
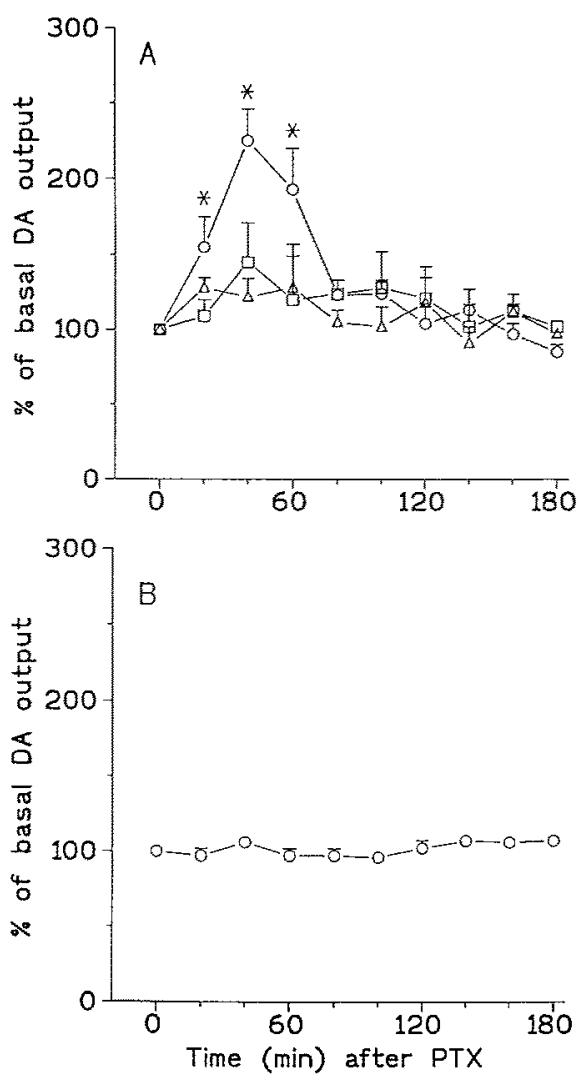

Fig. $6 \mathrm{~A}, \mathbf{B}$ Effect of picrotoxin (PTX) $(\triangle 0.50 \mathrm{mg} / \mathrm{kg} \mathrm{SC}$; $0.75 \mathrm{mg} / \mathrm{kg} \mathrm{SC} ; \bigcirc 1 \mathrm{mg} / \mathrm{kg} \mathrm{SC}$ ) on DA output in dialysates from the prefrontal cortex (A) and from the nucleus accumbens (B). Results are means $\pm S E M$ of the results obtained in at least four rats. * $P<0.05$ compared with basal values 

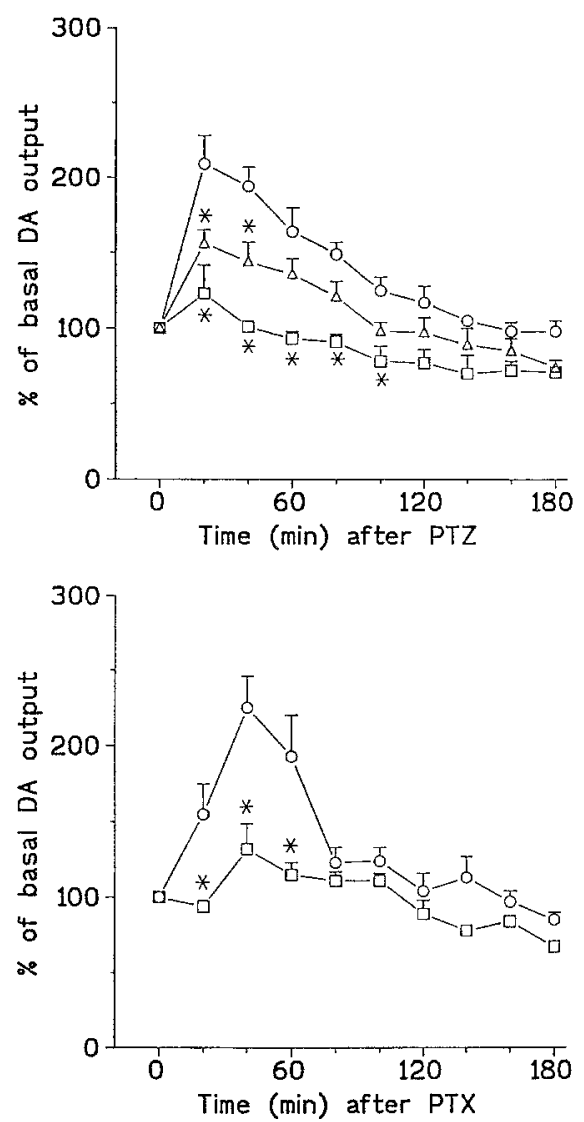

Fig. 8 Effect of the $5 \mathrm{HT}_{3}$ antagonist ICS $205930(15$ and $30 \mu \mathrm{g} /-$ $\mathrm{kg} \mathrm{SC}$ ) on DA output in dialysates from the rat prefrontal cortex administered $1 \mathrm{~h}$ before pentylentetrazole (PTZ, top) $20 \mathrm{mg} / \mathrm{kg}$ IP or picrotoxin $(P T X$, bottom $1 \mathrm{mg} / \mathrm{kg} \mathrm{SC}$. Results are means $\pm \mathrm{SEM}$ of the results obtained in at least four rats. $\bigcirc$ Saline SC+PTZ 20 $\mathrm{mg} / \mathrm{kg}$ IP or PTX $1 \mathrm{mg} / \mathrm{kg} \mathrm{SC} ; \triangle \mathrm{ICS} 20593015 \mu \mathrm{g} / \mathrm{kg} \mathrm{SC}+\mathrm{PTZ}$ $20 \mathrm{mg} / \mathrm{kg}$ IP; $\square$ ICS $30 \mu \mathrm{g} / \mathrm{kg}$ SC+PTZ $20 \mathrm{mg} / \mathrm{kg}$ IP or PTX $1 \mathrm{mg} / \mathrm{kg}$ SC. ${ }^{*} P<0.05$ compared with saline+PTZ or saline+PTX 